\title{
Commentary: By the few, for the few
}

\author{
Dawn S. Hui, MD, and Richard Lee, MD, MBA
}

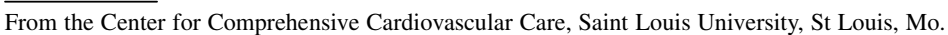

Disclosures: Authors have nothing to disclose with regard to commercial support.

Received for publication Oct 16, 2018; accepted for publication Oct 18, 2018; available ahead of print Dec 8, 2018.

Address for reprints: Dawn S. Hui, MD, 3635 Vista Ave, 15th Floor, St Louis, MO 63110 (E-mail: richardleemdmba@gmail.com).

J Thorac Cardiovasc Surg 2019;157:2278

$0022-5223 / \$ 36.00$

Copyright (C) 2018 by The American Association for Thoracic Surgery

https://doi.org/10.1016/j.jtcvs.2018.10.096

The benefits of off-pump coronary artery bypass (OPCAB) remain an area of debate for cardiac surgeons. In this edition of the Journal, Dr Angelini ${ }^{1}$ provides his perspective on $\mathrm{OPCAB}$ from 25 years of personal experience and as an observer of its evolution. With respect to those surgeons who should practice $\mathrm{OPCAB}$, he first regarded it as a technique that was "for the many and not the few." ${ }^{1}$ As he recounts, his initial enthusiasm has been tempered by a recognition that the Achilles' heel of OPCAB is incomplete revascularization. He concludes that $\mathrm{OPCAB}$ is currently a technique "for the few" surgeons, with the potential to become "for the many" if the right training structure and environment are provided. This focus is misdirected. What is not debated is that multiple studies have shown that OPCAB achieves inferior revascularization. Dr Angelini discusses the role of experience, institution, and wisdom in knowing when to convert as important factors to increase both adoption of OPCAB and completeness of revascularization. The data have never clearly demonstrated superior outcomes generally, however, and certainly no mortality benefit. We must therefore ask, why persist in pursuing dissemination of a technique that is not superior? Most optimistically, the best that can be achieved is noninferiority and not superiority. In fact, Chikwe and colleagues ${ }^{2}$ recently demonstrated that even among experienced surgeons with more than $100 \mathrm{OPCAB}$ cases (the very same threshold number proposed by Dr Angelini ${ }^{1}$ ), OPCAB was still associated with incomplete revascularization,

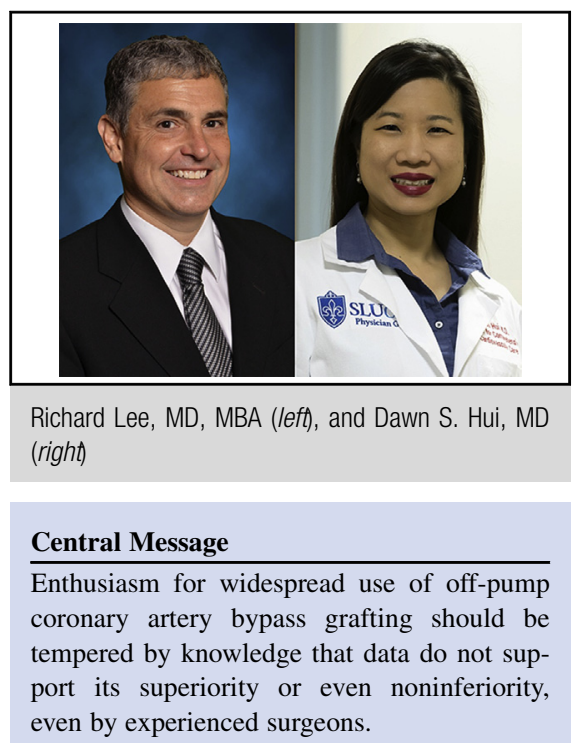

See Article page 2274.

higher repeat revascularization rates, and greater mortality. Young surgeons are right to be reluctant to adopt a technique that comes with a steep learning curve and a risk of deleterious outcomes, where superior outcomes cannot be assured and may only start to be achieved after numerous patients have been put at risk. We therefore propose that OPCAB be a technique reserved "by the few, for the few," such as patients with porcelain aorta and no percutaneous options.

\section{References}

1. Angelini GD. An old off-pump coronary artery bypass surgeon's reflections: a retrospective. J Thorac Cardiovasc Surg. 2019;157:2274-7.

2. Chikwe J, Lee T, Itagaki S, Adams DH, Egorova NN. Long-term outcomes after off-pump versus on-pump coronary artery bypass grafting by experienced surgeons. J Am Coll Cardiol. 2018;72:1478-86. 